\title{
Hot Topic: Prepubertal Ovariectomy Alters the Development of Myoepithelial Cells in the Bovine Mammary Gland
}

\author{
K. Ballagh, ${ }^{*}$ N. Korn, ${ }^{*}$ L. Riggs, $†$ S. L. Pratt, ${ }^{*}$ F. Dessauge,‡ R. M. Akers,§ and S. Ellis ${ }^{\star 1}$ \\ *Animal and Veterinary Sciences Department, Clemson University, Clemson, SC 29634 \\ †School of Veterinary Medicine, Louisiana State University, Baton Rouge 70803 \\ †Institut National de la Recherche Agronomique (INRA) Unité Mixte de Recherches sur la Production du Lait, Saint Gilles, France \\ $\S$ Department of Dairy Science, Virginia Polytechnic Institute and State University, Blacksburg 24061
}

\begin{abstract}
Prepubertal ovariectomy can dramatically inhibit mammary development, but the mechanism of inhibition is not well characterized. Holstein heifers were ovariectomized (OVX) or sham operated but left intact (INT) at d 40 and then sacrificed at d 55, 70, 85, 100, 130 , or 160 to provide tissues for histologic analysis of cell proliferation. Our histologic analyses unexpectedly revealed a pronounced effect of ovariectomy on myoepithelial cell development. Myoepithelial cells were identified on the basis of location, morphology, and immunohistochemical staining for $\alpha$-smooth muscle actin (SMA). Vascular smooth muscle staining served as an internal positive control for all immunohistochemical analyses. Mammary tissues from d 40 heifers had an abundance of SMA+ cells associated with the ductal parenchyma. In INT heifers, the frequency of SMA+ cells decreased as development progressed. Only a limited number of isolated SMA+ cells were observed in d 70 to $\mathrm{d} 160$ INT heifers. In OVX heifers, SMA+ cells were abundant, had elongated morphology, and frequently stained more intensively than vascular smooth muscle cells. The intense SMA staining and altered morphology was most prominent in older heifers. Limited analysis of gene expression revealed that maspin, a protease inhibitor expressed by myoepithelial cells, was expressed in parenchyma from both INT and OVX heifers. Our hypothesis is that ovarian secretions stimulate epithelial proliferation, and block myoepithelial differentiation. Myoepithelial cells are known to limit parenchymal cell proliferation. Ovariectomy may thus remove an estrogenic growth stimulus and permit the emergence of inhibitory cell populations that further limit parenchymal expansion. Our observation has important implications for control mechanisms that regulate parenchymal development.
\end{abstract}

Received March 18, 2008.

Accepted May 21, 2008.

${ }^{1}$ Corresponding author: ellis@clemson.edu
Key words: ovariectomy, myoepithelial, parenchymal development

Sinha and Tucker (1969) showed that allometric growth of mammary parenchyma begins well before puberty in heifers. Ovariectomy can inhibit allometric mammary development (e.g., Wallace, 1953; Purup et al., 1993), but the mechanisms of ovarian influence on prepubertal mammary development are poorly defined. Berry et al. (2003) reported that heifers ovariectomized earlier than $\sim 2.5$ mo of age had virtually no subsequent mammary parenchymal growth. Heifers ovariectomized between 2.5 and 3.0 mo of age had reduced, but not completely impaired, mammary growth. The agedependent effects of ovariectomy suggest that prepubertal ovarian activity is especially important in determining the rate and extent of mammary development. During a recent trial to assess the effect of prepubertal ovariectomy on proliferative parenchymal cell populations, we noted an unexpected and dramatic effect on the appearance of myoepithelial cells after ovariectomy.

Thirty-nine Holstein heifers were purchased from regional suppliers between 7 and $21 \mathrm{~d}$ of age. Commercial milk replacer and starter ration were fed according to manufacturer's instructions. At d 40 of age, all heifers underwent flank laparotomy to perform either an ovariectomy (OVX; $\mathrm{n}=16)$ or sham (INT; $\mathrm{n}=21$ ) operation. All procedures were approved and monitored by the Clemson University Institutional Animal Care and Use Committee. At 55, 70, 85, 100, 130, or $160 \mathrm{~d}$ of age, INT and OVX heifers were sacrificed to provide tissues for histologic analysis. Two INT heifers were sacrificed at d 40 to serve as a control for developmental divergence for both INT and OVX heifers. Parenchymal tissues were fixed in $4 \%$ paraformaldehyde in $\mathrm{pH} 7.2$ PBS overnight, dehydrated through a graded series of ethanol solutions $(50,75,95,100$, and $100 \%)$, infiltrated, and embedded in ImmunoBed resin according to the manufacturer's instructions (Polysciences Inc., Warrington, PA). To detect smooth muscle actin (SMA), sections (1.5 
$\mu \mathrm{m})$ were stained with a prediluted primary antibody (anti-SMA IMMH2, Sigma, St. Louis, MO) and secondary gold-conjugated antibody (10 $\mathrm{nm}$ goat-anti-rabbit, $0.6 \mathrm{~g} / \mathrm{mL}$ working concentration as a 1:50 dilution of the stock; BBInternational, Lianishen, UK). Silver enhancement (BBInternational) was performed according to the manufacturer's instructions, and sections were counterstained with sequential immersions in $1 \%$ Azure II in a $1 \%$ Na-borate buffer and $1 \%$ basic fuchsin in $2.5 \%$ ethanol.

Primer pairs for PCR were designed to analyze the expression of maspin, a protease inhibitor expressed by myoepithelial cells (Zou et al., 1994), in mammary tissue samples after reverse transcription of total cellular RNA using the Superscript III kit according to manufacturer's protocols (Invitrogen, Carlsbad, CA). The maspin primers (forward: 5'-ATGCCAAAGTCAAACTCTCCAT-3' and reverse: 5'-GACATCCCAGAGAAATCAGAGG-3') were used in a standard 35-cycle reverse transcription-PCR reaction with $30 \mathrm{~s}$ of denaturation at $94^{\circ} \mathrm{C}, 30 \mathrm{~s}$ of annealing at $60^{\circ} \mathrm{C}$, followed by extension for $30 \mathrm{~s}$ at $72^{\circ} \mathrm{C}$ in each cycle. The PCR product was subcloned and sequenced to ensure that the amplified product was maspin. Results of the BLAST search (http://www.ncbi.nlm.nih.gov/blast/Blast.cgi) showed several bovine expressed sequence tags with $100 \%$ identity and $\geq 90 \%$ homology for equine, human, chimpanzee, and orangutan maspin sequences (data not shown).

Parenchymal tissues in 15 or more randomly selected microscope fields from several nonadjacent sections were observed to count at least 1,000 cells per animal, resulting in a total of 42,245 cell observations. Basal position within the parenchymal epithelium, positive immunoreactivity for SMA, and cell morphology were used to identify and characterize myoepithelial cells (Deugnier et al., 1995). Parenchymal cells were assessed for SMA staining and scored as SMA- or SMA+. Cells in the SMA+ category had staining patterns that ranged from sparsely distributed punctate staining to heavy continuous staining. Cells with more intense staining tended to have the elongated cytoplasmic processes expected of differentiated myoepithelial cells. Intense staining was also found in some rounded cells in the basal strata, suggesting a series of progressive differentiation stages. The present experimental design provided no context to discern sequential stages of myoepithelial differentiation once they became SMA+, so the staining results are presented in a conservative manner with only 2 categories (SMA+ and SMA-). Statistical analyses were performed with Z-tests to compare the proportion of SMA+ cells at each age. The $P$ values were adjusted using the Bonferroni procedure and considered significant if the adjusted $P$-values were $<0.05$.
Vascular smooth muscle staining served as an internal positive control for SMA+ staining. Vascular smooth muscle cells were identified on the basis of their fusiform shape, association with endothelial cells, and position within the vascular tunica media. There were no noticeable differences in smooth muscle morphology in samples from OVX or INT heifers. The SMA staining in vascular smooth muscle cells had a consistent and moderate intensity that served as a convenient reference during observation of histologic sections.

Figure 1 includes representative micrographs of parenchymal tissues from d 40 control, and d 100 INT and OVX heifers (panels A to C). Our interest in myoepithelial cells and SMA staining was sparked by the observation of strikingly altered basal cell morphology in samples from OVX heifers. During the processing of coded mammary tissue samples, it became very obvious from inspection of Azure II and basic-fuchsin'stained sections that 2 distinct morphologies were present in our samples (data not shown). One set of slides had the typical rounded basal cell morphology we have come to expect after numerous experiments with normal, intact heifers (e.g., Capuco et al., 2002). In the other set of slides, basal cells had extended cytoplasmic processes, rich cytoplasmic staining, and were associated with altered epithelial stratification patterns. When the sample codes were checked, all of the OVX heifers had the altered basal cell histomorphology. In OVX heifers most of the parenchymal epithelium was organized into a single layer of lumenal cells and an essentially continuous layer of basal myoepithelial cells. Our observations of altered gross tissue histology prompted us to stain for SMA as an indicator of myoepithelial differentiation.

As depicted in Figure 1 (panel D), our quantitative assessment of SMA labeling in histologic samples from OVX and INT heifers validated our subjective impressions of altered myoepithelial cell populations. In samples from heifers slaughtered at d $40(n=2), 80 \%$ of basal epithelial cells were SMA+. By d 55, only $27 \%$ of basal parenchymal cells in INT heifers were SMA+ $(P$ $<0.05$ relative to $\mathrm{d} 40$ ), and SMA staining was not observed in the micrographs collected from the INT $d$ 70 samples $(P<0.05$ relative to d 40$)$. After d 55, labeling for SMA remained greater $(P<0.05)$ in OVX $(>47 \%)$ than in INT $(<0.6 \%)$. At later ages, SMA+ cells in OVX heifers tended to have much more pronounced SMA staining and more elongated cell morphology. The few SMA+ cells observed in INT heifers after d 55 tended to have only a very light, diffuse SMA staining pattern (data not shown). The very low frequency of SMA+ cells observed in intact heifers (e.g., $0.6 \%$ at d 100) suggests that although ovarian secretions can suppress myoepithelial differentiation, there is no absolute lack of myoepithelial cells in intact heifers. It is therefore possible 


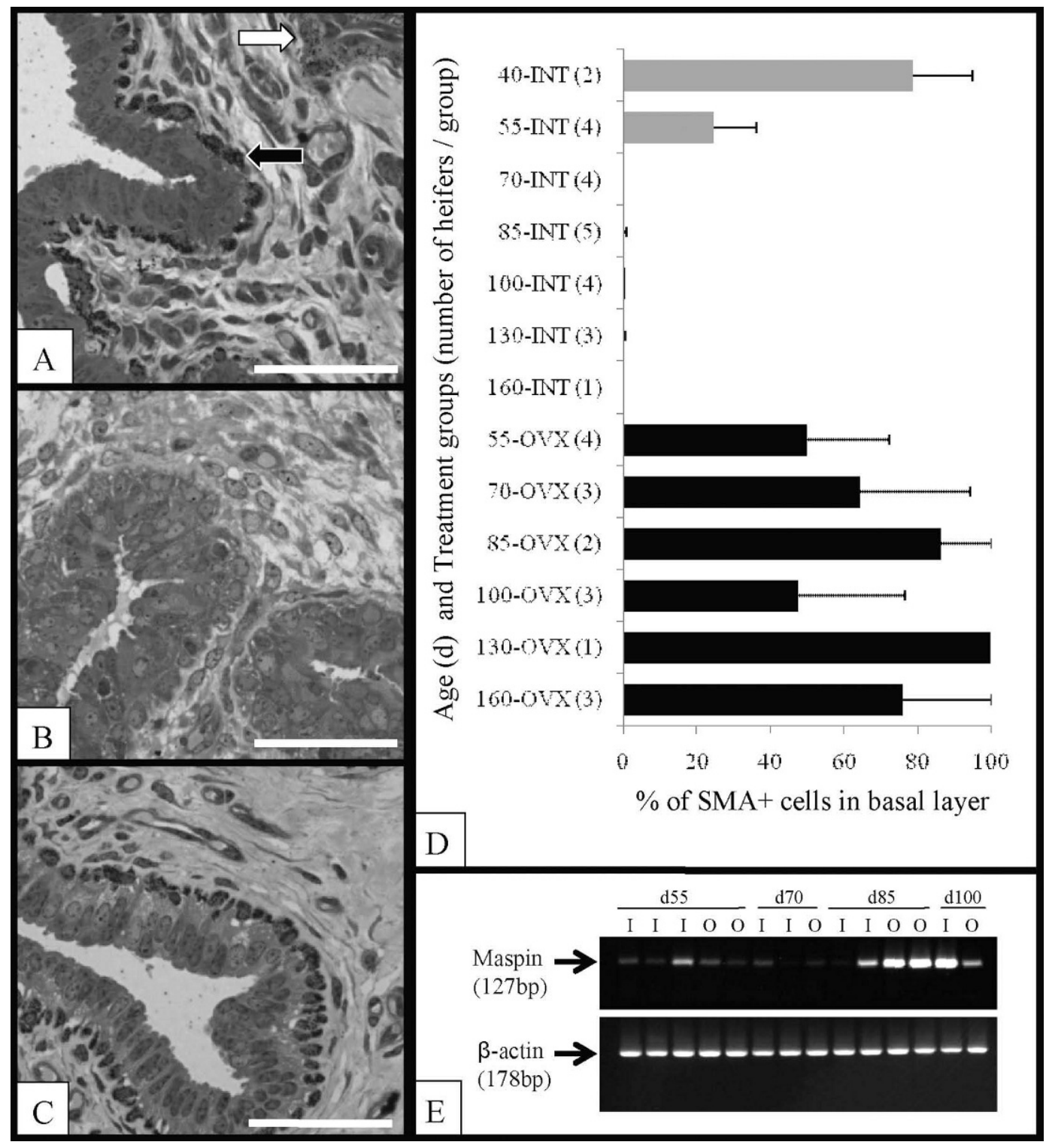

Figure 1. The effect of ovariectomy on myoepithelial development in prepubertal heifers. Representative micrographs of tissues from a control heifer killed at $40 \mathrm{~d}$ of age (panel A), intact (INT) animal at $100 \mathrm{~d}$ (panel B), and ovariectomized (OVX) animal at $100 \mathrm{~d}$ (panel C) are shown to illustrate the observed differences in basal cell morphology and smooth muscle actin (SMA) staining. Scale bars (in white) indicate $50 \mu \mathrm{m}$. Positive SMA (SMA+) staining is visible in panels A and C but is essentially absent in panel B. Note that staining for SMA in myoepithelial cells (panel A, dark arrow) was frequently more intense than vascular SMA staining (panel A, white arrow). Panel D illustrates the quantitative assessment of SMA staining of cells in the basal stratum of parenchymal epithelia from INT (gray bars) and OVX (black bars) heifers. Each bar represents the average percentage of SMA+ cells in a given treatment group, as indicated (mean \pm SE). Panel E depicts the results of our reverse transcription-PCR analysis for maspin expression. Although our present results are not quantitative, maspin expression in the prepubertal bovine mammary gland has not been previously reported, but was detected in both INT (I) and OVX (O) heifers.

that myoepithelial cells are transiently involved in morphogenesis and ductal patterning. Reverse transcription-PCR confirmed that maspin was expressed in both INT and OVX heifers (Figure 1, panel E). The expression of maspin has not been previously reported in prepubertal bovine mammary parenchyma, so our data provide the first potential mechanistic insights into a role for myoepithelial secretions in prepubertal mammary development.

In total, our observations suggest that ovariectomy of prepubertal Holstein heifers leads to precocious myoepithelial differentiation or to myoepithelial persistence past d 40 and the onset of allometry. In either case, the population of parenchymal cells is markedly 
altered, with potentially profound physiologic consequences. In addition to having contractile properties, mammary myoepithelial cells in humans and mice may regulate the growth and differentiation of neighboring lumenal cells (for review, see Gudjonsson et al., 2006). Myoepithelial cells are reported to have a tumor-suppressing role in the mammary gland, suggesting that they may inhibit the proliferation of both normal cells and parenchymal tumors. We hypothesize that ovarian factors prevent the differentiation of the myoepithelial cells in prepubertal heifers to allow for normal parenchymal growth. Ovariectomy would permit early myoepithelial differentiation and expression of growth inhibitors, resulting in the underdeveloped ducts seen in OVX heifers.

Ovarian factors, presumably estrogen, may inhibit differentiation indirectly. First, estrogen levels in prepubertal heifers are generally quite low and change only marginally after ovariectomy (Purup et al., 1993; Berry et al., 2003). Heifers ovariectomized at $2.5 \mathrm{mo}$ showed a significant decrease in estrogen levels (Purup et al., 1993), but the magnitude of the difference was only $0.1 \mathrm{pg} / \mathrm{mL}$. Purup et al. (1993) observed an 80 to $90 \%$ decrease in parenchymal development in OVX heifers, so it seems unlikely that such an incremental decline in estrogen concentrations would account for the entire ovariectomy effect. We have also noted a dissociation between estrogen receptors and proliferating epithelial cells that further suggests the effects of estrogen are mediated by paracrine mechanisms (Capuco et al., 2002). In support of our hypothesis that myoepithelial cells inhibit parenchymal development, INT heifers showed a decrease in the amount of SMA label following $d 40$, such that myoepithelial cells were very rarely observed in INT heifers after $d 55$. Thus, myoepithelial cells were largely absent from the mammary gland of INT heifers during a rapid growth phase. We have previously noted an apparent lack of myoepithelial cells in intact prepubertal heifers (Capuco et al., 2002), but failed to appreciate the fact that ovariectomy caused a major alteration in myoepithelial development (Berry et al., 2003), likely because of a heavy reliance on paraffin-based histology. In the present study, the detection of myoepithelial cells was facilitated by the use of semi-thin resin histology techniques to provide high-resolution visualizations of parenchymal cell histology. Without such detailed histologic information, it is doubtful that the alterations in basal cell morphology would have been noted.

A further understanding of early myoepithelial cell ontogeny is necessary to define ovarian effects on mammary tissue, especially during the neonatal period. Fu- ture studies should include quantitative assessment of growth factor expression by myoepithelial cells because temporal variations in expression, abundance, and distribution of paracrine regulators of parenchymal development by myoepithelial cells could help explain inhibition of parenchymal growth in ovariectomized heifers. Furthermore, our observation suggests that if estrogenic modulation of myoepithelial cell populations occurs prepubertally and causes marked effects on mammary development, it may be possible to manipulate myoepithelial cells in the adult mammary gland to maximize milk production.

\section{ACKNOWLEDGMENTS}

This project was supported by National Research Initiative Competitive Grant no. 2006-35206-16699 from the USDA Cooperative State Research, Education, and Extension Service. Numerous individuals contributed to the care of heifers and sample collection required for this trial, including H. Barton, J. Campbell, E. Curry, S. Duckett, D. Duffy, J. Fain, C. Floyd, S. Kuper, and A. Reed. This material is based upon work supported by CSREES/USDA, under project number SC-1700250 and has been assigned Technical Contribution No. 5458 of the Clemson University Experiment Station.

\section{REFERENCES}

Berry, S. D., P. M. Jobst, S. Ellis, R. Howard, A. V. Capuco, and R. M. Akers. 2003. Mammary epithelial proliferation and estrogen receptor $\alpha$ expression in prepubertal heifers: Effects of ovariectomy and growth hormone. J. Dairy Sci. 86:2098-2105.

Capuco, A. V., S. Ellis, D. L. Wood, R. M. Akers, and W. Garrett. 2002. Postnatal mammary ductal growth: Three-dimensional imaging of cell proliferation, effects of estrogen treatment, and expression of steroid receptors in prepubertal calves. Tissue Cell 34:143-154.

Deugnier, M. A., E. P. Moiseyeva, J. P. Thiery, and M. Glukhova. 1995. Myoepithelial cell differentiation in the developing mammary gland: Progressive acquisition of smooth muscle phenotype. Dev. Dyn. 204:107-117.

Gudjonsson, T., M. C. Adriance, M. D. Sternlicht, O. W. Petersen, and M. J. Bissell. 2006. Myoepithelial cells: Their origin and function in breast morphogenesis and neoplasia. J. Mammary Gland Biol. Neoplasia 10:261-272.

Purup, S., K. Sejrsen, J. Foldager, and R. M. Akers. 1993. Effects of exogenous bovine growth hormone and ovariectomy on prepubertal mammary growth, serum hormones, and acute in vitro proliferative response of mammary explants form Holstein heifers. J. Endocrinol. 139:19-26.

Sinha, Y. N., and H. A. Tucker. 1969. Mammary development and pituitary prolactin level of heifers from birth through puberty and during estrus cycle. J. Dairy Sci. 52:507-512.

Wallace, C. 1953. Observations on mammary development in calves and lambs. J. Agric. Sci. 43:413-421.

Zou, Z., A. Anisowicz, M. J. Hendrix, A. Thor, M. Neveu, S. Sheng, K. Rafidi, E. Seftor, and R. Sager. 1994. Maspin, a serpin with tumor-suppressing activity in human mammary epithelial cells. Science 263:526-529. 